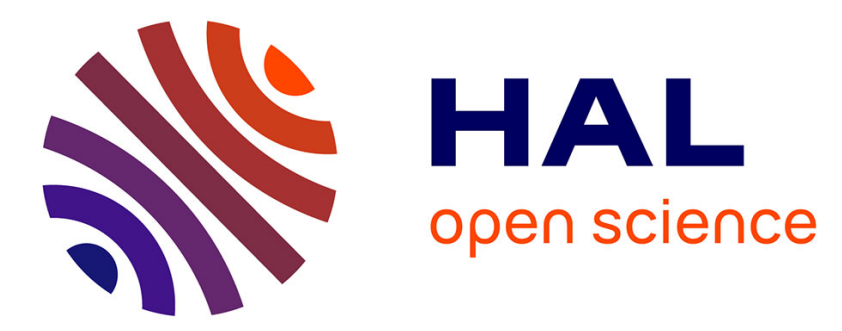

\title{
Concrete modeling for neutron transport and associated sensitivity studies performed at the AMANDE-MIRCOM facility
}

\author{
Michael Petit
}

\section{- To cite this version:}

Michael Petit. Concrete modeling for neutron transport and associated sensitivity studies performed at the AMANDE-MIRCOM facility. Nuclear Science and Engineering, 2021, 10.1080/00295639.2020.1867436 . hal-03133956

\section{HAL Id: hal-03133956 \\ https://hal.science/hal-03133956}

Submitted on 7 Feb 2021

HAL is a multi-disciplinary open access archive for the deposit and dissemination of scientific research documents, whether they are published or not. The documents may come from teaching and research institutions in France or abroad, or from public or private research centers.
L'archive ouverte pluridisciplinaire HAL, est destinée au dépôt et à la diffusion de documents scientifiques de niveau recherche, publiés ou non, émanant des établissements d'enseignement et de recherche français ou étrangers, des laboratoires publics ou privés.

\section{(1) (1) $\$$}

Distributed under a Creative Commons Attribution - NonCommercial - NoDerivatives $\mid 4.0$ 
Concrete modeling for neutron transport and associated sensitivity studies performed at the AMANDE-MIRCOM facility

Michaël Petit

Micro-irradiation, neutron metrology and dosimetry laboratory (LMDN); Institute for Radiological Protection and Nuclear Safety (IRSN), Cadarache - Bat. 159 BP 3, 13115 SaintPaul-lez-Durance Cedex, France

Corresponding author: michael.petit@irsn.fr 


\title{
Concrete modeling for neutron transport and associated sensitivity studies performed at the AMANDE-MIRCOM facility
}

\begin{abstract}
Concrete plays a major role in nuclear facilities as protection against radiation. However, its chemical composition, which is fundamental, is often unknown. Several concrete samples, extracted from the AMANDE-MIRCOM IRSN facility, were analysed. Various simulations were performed in order to evaluate the neutron fluence behind a $40 \mathrm{~cm}$ thick concrete wall. These simulations were compared to experimental measurements performed with a Bonner Sphere spectrometer and a neutron survey meter. No set of parameters tested was able to produce a simulation accurately matching all the experimental results but sensitivity studies on several parameters highlight that the three most sensitive parameters are the hydrogen content, the density and the concrete inhomogeneity. To improve the agreement between the simulations and measurements, the concrete inhomogeneity modeling should be studied further. Nevertheless, using concrete compositions that are close to reality, especially for hydrogen content, is crucial to correctly simulate neutron transport.
\end{abstract}

Keywords - concrete, shielding, modeling, neutrons, radiation protection.

\section{INTRODUCTION}

Concrete is often used for protection against radiation in nuclear facilities. Indeed, this material has many structural qualities and is very efficient in reducing radiation levels. The accurate chemical composition of the concrete has to be known to correctly simulate particle transport, in particular neutron and gamma. However, few data like in the "Compendium of Material Composition Data for Radiation Transport Modeling" of the Pacific Northwest National Laboratory ${ }^{1}$ are available and moreover it is difficult to know what data should be used in simulations. In "Radiation Shielding" of J. K. Shultis and R. E. Faw 2, "typical compositions" for two "ordinary" concretes (NBS 03 and 04) and five "special" concretes (Magnetite, Barytes, etc.) are proposed. However, only the main elements are indicated without extensive details. Even in the fairly complete book ${ }^{3}$ of more than 900 pages devoted to concrete, no clear chemical composition by element is given, with little discussion of 
concrete radiation protection issues. Furthermore, the typical compositions found in the literature, like in the "Specification for radiation shielding materials" of the American Nuclear Society ${ }^{4}$, do not explicitly justify particular measurements.

In this study, the chemical composition of three different concretes was accurately determined experimentally. All three were used in the construction of the AMANDEMIRCOM facility ${ }^{5}$. Then, neutron spectrometry and dosimetry measurements were done in this facility behind a $40 \mathrm{~cm}$ thick concrete wall ${ }^{6}$. These measurements were compared to MCNP calculations including a sensitivity study of the main model parameters and also to several different types of concrete proposed in the literature.

\section{CONCRETE FEATURES}

\section{II.A. Chemical composition}

During the construction of an extension at the AMANDE facility in 2014, three sets of concrete samples from $2 \mathrm{~kg}$ to $20 \mathrm{~kg}$ were obtained. The first set (called "AMANDE") came from core drilling carried out in the part of the facility built in 2003. The second and third set (called respectively "MIRCOM" and "pre-wall") came from the extension built in 2014. Some of these samples (six "AMANDE", eight "MIRCOM" and three "pre-wall") were sent to Arcane (CENBG-France) for analysis in 2016 to determine -as accurately as possible- their chemical composition. These compositions were obtained for all elements ${ }^{7}$ with the exception of boron, as it would had require additional analysis. However, boron was not reasonably expected in these concrete samples, as no special request for adding it was made during the construction.

Table I summarizes the results with the average, minimum and maximum mass percentage of each element as well as the corresponding standard deviation. The measured values are consistent with the data found in the literature. In particular, the measured average hydrogen level $(0.86 \%, 0.65 \%$ and $0.47 \%)$, is in agreement with the values generally 
indicated for equivalent concretes (usually between $0.5 \%$ and $1.0 \%$ ). Even both free and bound water measurements were performed and the sensitivity analysis considers that the amount of hydrogen could be underestimated. These results are given without taking into account steel reinforcement. These compositions are relatively close to the three concrete compositions proposed in ${ }^{1:}$ "material $n^{\circ} 94$ : Oak Ridge (ORNL)", "material n 95 : Ordinary (NBS 03)" and "material $n^{\circ} 100$ : Rocky Flats". It is noteworthy that there is no trace of boron in these compositions. The measurements carried out in the present work also include the values of the trace elements (down to a few ppm), as some of them could be important for activation calculations.

Table I: Chemical composition of the concrete samples for each set.

\begin{tabular}{|c|c|c|c|c|c|c|c|c|c|c|c|c|c|}
\hline \multicolumn{2}{|c|}{ in mass percentage } & \multicolumn{4}{|c|}{ AMANDE (6 samples) } & \multicolumn{4}{|c|}{ MIRCOM (8samples) } & \multicolumn{4}{|c|}{ Pre-wall (3 samples) } \\
\hline $\begin{array}{l}\text { Atomic } \\
\text { number }\end{array}$ & $\begin{array}{l}\text { chemical } \\
\text { symbol }\end{array}$ & average & $\begin{array}{l}\text { Standard } \\
\text { deviation }\end{array}$ & Махіпиm & Minimum & average & $\begin{array}{l}\text { Standard } \\
\text { deviation }\end{array}$ & Maxinum & Minimum & average & $\begin{array}{l}\text { Standard } \\
\text { deviation }\end{array}$ & Maximum & Minimum \\
\hline 1 & $\mathrm{H}$ & $6,5 \mathrm{E}-01$ & $5,5 \mathrm{E}-02$ & $7,0 \mathrm{E}-01$ & $6,0 \mathrm{E}-01$ & $8,6 \mathrm{E}-01$ & $1,4 \mathrm{E}-01$ & $1,1 \mathrm{E}+00$ & $7,0 \mathrm{E}-01$ & $4,7 \mathrm{E}-01$ & $5,8 \mathrm{E}-02$ & $5,0 \mathrm{E}-01$ & $4,0 \mathrm{E}-01$ \\
\hline 6 & $\mathrm{C}$ & $6,4 \mathrm{E}+00$ & $3,7 \mathrm{E}-01$ & $6,8 \mathrm{E}+00$ & $5,8 \mathrm{E}+00$ & $7,4 \mathrm{E}+00$ & $6,3 \mathrm{E}-01$ & $8,9 \mathrm{E}+00$ & $6,9 \mathrm{E}+00$ & $9,6 \mathrm{E}+00$ & $1,2 \mathrm{E}-01$ & $9,7 \mathrm{E}+00$ & $9,5 \mathrm{E}+00$ \\
\hline 7 & $\mathrm{~N}$ & $2,0 \mathrm{E}-01$ & $3,0 \mathrm{E}-17$ & $2,0 \mathrm{E}-01$ & $2,0 \mathrm{E}-01$ & $1,9 \mathrm{E}-0 \mathrm{I}$ & $3,5 \mathrm{E}-02$ & $2,0 \mathrm{E}-01$ & $1,0 \mathrm{E}-01$ & $2,0 \mathrm{E}-01$ & $3,4 \mathrm{E}-17$ & $2,0 \mathrm{E}-01$ & $2,0 \mathrm{E}-01$ \\
\hline 8 & 0 & $4,6 \mathrm{E}+01$ & $2,0 \mathrm{E}+00$ & $4,9 \mathrm{E}+01$ & $4,4 \mathrm{E}+01$ & $4,7 \mathrm{E}+01$ & $2,4 \mathrm{E}+00$ & $5,0 \mathrm{E}+01$ & $4,3 \mathrm{E}+01$ & $4,4 \mathrm{E}+01$ & $1,2 \mathrm{E}+00$ & $4,6 \mathrm{E}+01$ & $4,4 \mathrm{E}+01$ \\
\hline 12 & $\mathrm{Mg}$ & $6,5 \mathrm{E}-01$ & $3,2 \mathrm{E}-01$ & $1,1 \mathrm{E}+00$ & $3,0 \mathrm{E}-01$ & $5,1 \mathrm{E}-01$ & $3,1 \mathrm{E}-01$ & $9,0 \mathrm{E}-01$ & $0,0 \mathrm{E}+00$ & $7,3 \mathrm{E}-01$ & $4,0 \mathrm{E}-01$ & $1,1 \mathrm{E}+00$ & $3,0 \mathrm{E}-01$ \\
\hline 13 & $\mathrm{~A} 1$ & $1,7 \mathrm{E}+00$ & $3,5 \mathrm{E}-01$ & $2,2 \mathrm{E}+00$ & $1,3 \mathrm{E}+00$ & $1,6 \mathrm{E}+00$ & $2,3 \mathrm{E}-01$ & $2,0 \mathrm{E}+00$ & $1,2 \mathrm{E}+00$ & $9,7 \mathrm{E}-01$ & $5,8 \mathrm{E}-02$ & $1,0 \mathrm{E}+00$ & $9,0 \mathrm{E}-01$ \\
\hline 14 & $\mathrm{Si}$ & $1,2 \mathrm{E}+01$ & $1,0 \mathrm{E}+00$ & $1,3 \mathrm{E}+01$ & $1,0 \mathrm{E}+01$ & $7,1 \mathrm{E}+00$ & $1,8 \mathrm{E}+00$ & $8,9 \mathrm{E}+00$ & $2,8 \mathrm{E}+00$ & $2,0 \mathrm{E}+00$ & $1,5 \mathrm{E}-01$ & $2,1 \mathrm{E}+00$ & $1,8 \mathrm{E}+00$ \\
\hline 16 & $\mathrm{~s}$ & $1,7 \mathrm{E}-01$ & $5,2 \mathrm{E}-02$ & $2,0 \mathrm{E}-0 \mathrm{l}$ & $1,0 \mathrm{E}-01$ & $2,1 \mathrm{E}-0 \mathrm{I}$ & $3,5 \mathrm{E}-02$ & $3,0 \mathrm{E}-0 \mathrm{l}$ & $2,0 \mathrm{E}-01$ & $1,7 \mathrm{E}-01$ & $5,8 \mathrm{E}-02$ & $2,0 \mathrm{E}-01$ & $1,0 \mathrm{E}-01$ \\
\hline 19 & $\mathrm{~K}$ & $4,0 \mathrm{E}-01$ & $6,3 \mathrm{E}-02$ & $5,0 \mathrm{E}-01$ & $3,0 \mathrm{E}-01$ & $3,8 \mathrm{E}-01$ & $89 \mathrm{E}-02$ & $5,0 \mathrm{E}-01$ & $2,0 \mathrm{E}-01$ & $2,7 \mathrm{E}-01$ & $5,8 \mathrm{E}-02$ & $3,0 \mathrm{E}-01$ & $2,0 \mathrm{E}-01$ \\
\hline 20 & $\mathrm{Ca}$ & $3,1 \mathrm{E}+01$ & $1,6 \mathrm{E}+00$ & $3,4 \mathrm{E}+01$ & $3,0 \mathrm{E}+01$ & $3,4 \mathrm{E}+01$ & $2,5 \mathrm{E}+00$ & $3,7 \mathrm{E}+01$ & $3,1 \mathrm{E}+01$ & $4,1 \mathrm{E}+01$ & $1,5 \mathrm{E}+00$ & $4,2 \mathrm{E}+01$ & $3,9 \mathrm{E}+01$ \\
\hline 22 & $\mathrm{Ti}$ & $8,4 \mathrm{E}-02$ & $1,9 \mathrm{E}-02$ & $1,2 \mathrm{E}-01$ & $6,1 \mathrm{E}-02$ & $1,0 \mathrm{E}-01$ & $1,8 \mathrm{E}-02$ & $1,3 \mathrm{E}-01$ & $8,0 \mathrm{E}-02$ & $4,4 \mathrm{E}-02$ & $1,5 \mathrm{E}-03$ & $4,6 \mathrm{E}-02$ & $4,3 \mathrm{E}-02$ \\
\hline 24 & $\mathrm{Cr}$ & $4,9 \mathrm{E}-03$ & $1,8 \mathrm{E}-03$ & $7,9 \mathrm{E}-03$ & $2,9 \mathrm{E}-03$ & $3,1 \mathrm{E}-03$ & $1,4 \mathrm{E}-03$ & $5,4 \mathrm{E}-03$ & $6,0 \mathrm{E}-04$ & $2,3 \mathrm{E}-03$ & $1,5 \mathrm{E}-03$ & $3,7 \mathrm{E}-03$ & $7,0 \mathrm{E}-04$ \\
\hline 25 & $\mathrm{Mn}$ & $4,4 \mathrm{E}-02$ & $7,7 \mathrm{E}-03$ & $5,4 \mathrm{E}-02$ & $3,5 \mathrm{E}-02$ & $3,2 \mathrm{E}-02$ & $7,6 \mathrm{E}-03$ & $4,2 \mathrm{E}-02$ & $1,5 \mathrm{E}-02$ & $7,5 \mathrm{E}-03$ & $1,9 \mathrm{E}-03$ & $9,6 \mathrm{E}-03$ & $6,1 \mathrm{E}-03$ \\
\hline 26 & $\mathrm{Fe}$ & $8,7 \mathrm{E}-01$ & $1,0 \mathrm{E}-01$ & $1,0 \mathrm{E}+00$ & $7,0 \mathrm{E}-01$ & $8,3 \mathrm{E}-01$ & $2,0 \mathrm{E}-01$ & $1,1 \mathrm{E}+00$ & $5,0 \mathrm{E}-01$ & $5,3 \mathrm{E}-01$ & $5,8 \mathrm{E}-02$ & $6,0 \mathrm{E}-01$ & $5,0 \mathrm{E}-01$ \\
\hline 28 & $\mathrm{Ni}$ & $3,7 \mathrm{E}-03$ & $9,7 \mathrm{E}-04$ & $5,0 \mathrm{E}-03$ & $2,8 \mathrm{E}-03$ & $3,3 \mathrm{E}-03$ & $6,5 \mathrm{E}-04$ & $4,3 \mathrm{E}-03$ & $2,3 \mathrm{E}-03$ & $5,4 \mathrm{E}-03$ & $3,1 \mathrm{E}-04$ & $5,7 \mathrm{E}-03$ & $5,1 \mathrm{E}-03$ \\
\hline 29 & $\mathrm{Cu}$ & $4,5 \mathrm{E}-04$ & $4,0 \mathrm{E}-04$ & $1,1 \mathrm{E}-03$ & $0,0 \mathrm{E}+00$ & $8,6 \mathrm{E}-04$ & $5,3 \mathrm{E}-04$ & $1,5 \mathrm{E}-03$ & $1,0 \mathrm{E}-04$ & $5,2 \mathrm{E}-03$ & $3,6 \mathrm{E}-04$ & $5,5 \mathrm{E}-03$ & $4,8 \mathrm{E}-03$ \\
\hline 30 & $\mathrm{Zn}$ & $3,1 \mathrm{E}-03$ & $5,3 \mathrm{E}-04$ & $3,7 \mathrm{E}-03$ & $2,2 \mathrm{E}-03$ & $4,1 \mathrm{E}-03$ & $5,9 \mathrm{E}-04$ & $4,8 \mathrm{E}-03$ & $3,3 \mathrm{E}-03$ & $8,3 \mathrm{E}-03$ & $4,4 \mathrm{E}-04$ & $8,6 \mathrm{E}-03$ & $7,8 \mathrm{E}-03$ \\
\hline 37 & $\mathrm{Rb}$ & $1,7 \mathrm{E}-03$ & $2,4 \mathrm{E}-04$ & $2,0 \mathrm{E}-03$ & $1.3 \mathrm{E}-03$ & $1,5 \mathrm{E}-03$ & $7,3 \mathrm{E}-04$ & $2,7 \mathrm{E}-03$ & $6,0 \mathrm{E}-04$ & $6,7 \mathrm{E}-04$ & $5,9 \mathrm{E}-04$ & $1,1 \mathrm{E}-03$ & $0,0 \mathrm{E}+00$ \\
\hline 38 & $\mathrm{Sr}$ & $6,9 \mathrm{E}-02$ & $5,3 \mathrm{E}-03$ & $7,5 \mathrm{E}-02$ & $6,3 \mathrm{E}-02$ & $5,1 \mathrm{E}-02$ & $7,2 \mathrm{E}-03$ & $6,2 \mathrm{E}-02$ & $4,3 \mathrm{E}-02$ & $39 \mathrm{E}-02$ & $1,1 \mathrm{E}-03$ & $4,0 \mathrm{E}-02$ & $3,8 \mathrm{E}-02$ \\
\hline
\end{tabular}

\section{II.B. Density}

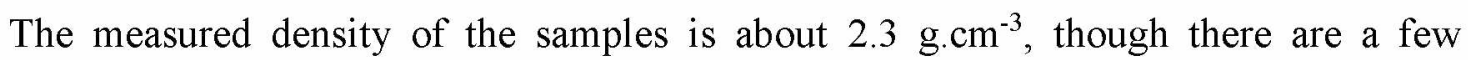
parameters to be considered when estimating the uncertainty of these values:

- the amount of steel in the concrete (not included in the Table I results) is usually between $50 \mathrm{~kg} \cdot \mathrm{m}^{-3}$ and $200 \mathrm{~kg} \cdot \mathrm{m}^{-3}$ depending on mechanical constraints;

- the air cavities represent from $1 \%$ to $10 \%$ of the volume according to ${ }^{3}$ and ${ }^{8}$, depending on the quality of the concrete; 
- in addition, we also discovered that concrete wall thicknesses at the facility, as measured by the core drilling samples, are up to $6 \%$ lower than the thicknesses indicated on the drawings.

As a result, uncertainty of at least $10 \%$ should be considered for the modeled concrete density.

\section{EXPERIMENTAL CONFIGURATIONS}

Neutron measurements were done in AMANDE facility's control room which is separated from the neutron experimental hall by a $40 \mathrm{~cm}$ concrete wall. Measurement of the energy distribution of the neutron fluence was performed with HERMEIS Bonner Sphere spectrometer ${ }^{9}$, completed by ambient dose equivalent determination at the same location with a Berthold LB6411 survey meter ${ }^{10}$. The geometry of the experimental configuration is shown in Figure 1.

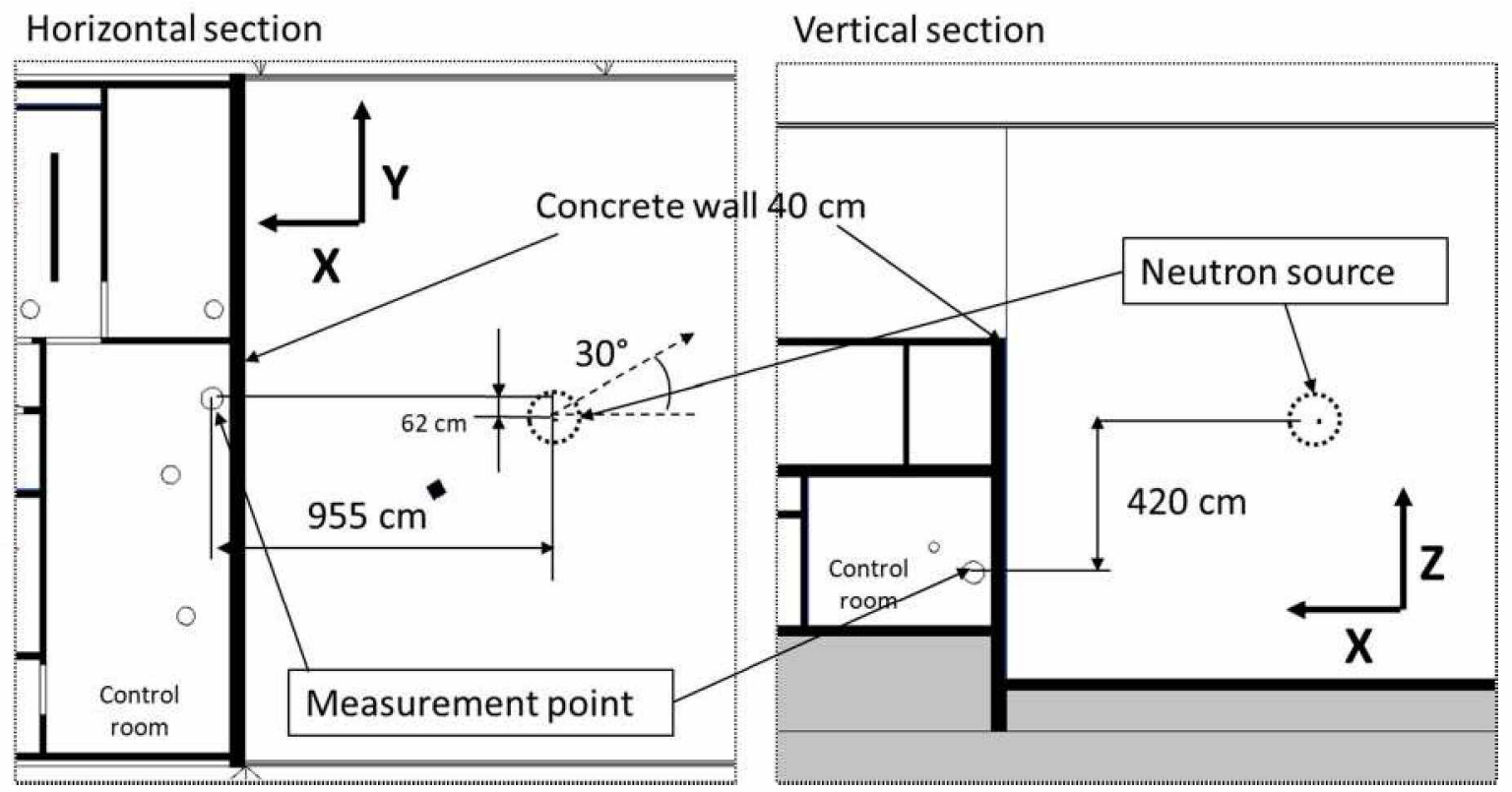

Figure 1: Drawing of the experimental configuration; Sections are given at the level of the measurement point. The direction of the beam $\left(0^{\circ}\right.$ axis for neutron production) is indicated by the dashed arrow starting from the neutron source on the horizontal section. The measuring point's direction is at $150^{\circ}$ with respect to this beam axis. Black lines are concrete walls, white volumes are filled with air and gray ones with others materials. 
For the present study, two mono-energetic neutron fields were produced in the AMANDE experimental hall ${ }^{5}$. The measurement position was chosen in such a way that the direct neutrons have to go only through the $40 \mathrm{~cm}$ thick concrete wall (and the ion beamline tube) before reaching the measurement position. AMANDE is an accelerator based facility, where neutrons are produced by an accelerated ion beam directed at a thin target. The two neutron sources used were produced with a $432 \mathrm{keV}$ deuteron beam, as follows:

1. Source 1: $\mathrm{T}(\mathrm{d}, \mathrm{n})^{4} \mathrm{He}$ reaction in a TiT target having a $\mathrm{T} / \mathrm{Ti}$ ratio of 1.45 and a thickness of $776 \pm 10 \mu \mathrm{g} . \mathrm{cm}^{-2}$. The energy of the neutrons produced at $0^{\circ}$ was of $15.1 \mathrm{MeV}$ whereas, in the direction of the measurement point behind the concrete wall $\left(150^{\circ}\right.$ emission angle), the neutron energy is of $13.33 \mathrm{MeV}$. The measured neutron emission rate was $4.54 \times 10^{8} \mathrm{~s}^{-1}$.

2. Source 2: $\mathrm{D}(\mathrm{d}, \mathrm{n})^{3} \mathrm{He}$ reaction in a TiD target having a $\mathrm{D} / \mathrm{Ti}$ ratio of 1.54 and a thickness of $793 \pm 11 \mu \mathrm{g} . \mathrm{cm}^{-2}$. The energies of the neutrons are respectively of $3.2 \mathrm{MeV}$ at $0^{\circ}$ and $2.05 \mathrm{MeV}$ in the direction of the measurement point behind the concrete wall $\left(150^{\circ}\right.$ emission angle). The measured neutron emission rate was $4.87 \times 10^{7} \mathrm{~s}^{-1}$

The neutron emission rates were used to normalize MCNP calculations. They were determined from fluence measurements performed with standard long counters ${ }^{11}$ in the experimental hall. The uncertainty on the emission rates is lower than $5 \%$. The total neutron fluence rate at the measuring point in the AMANDE control room, as determined with HERMEIS, is respectively $15.7 \pm 0.9 \mathrm{~cm}^{-2} \cdot \mathrm{s}^{-1}$ and $0.97 \pm 0.07 \mathrm{~cm}^{-2} \cdot \mathrm{s}^{-1}$ for source 1 and 2 . The ambient neutron dose equivalent rate has been determined from measurements with HERMEIS as well as with a LB6411 Berthold survey meter with the following values: 
1. Source 1: $9.5 \pm 0.7 \mu \mathrm{Sv} \cdot \mathrm{h}^{-1}$ and $8.2 \pm 0.1 \mu \mathrm{Sv} \cdot \mathrm{h}^{-1}$ respectively for HERMEIS and LB6411

2. Source 2: $0.24 \pm 0.02 \mu \mathrm{Sv} \cdot \mathrm{h}^{-1}$ and $0.24 \pm 0.03 \mu \mathrm{Sv} \cdot \mathrm{h}^{-1}$ respectively for HERMEIS and LB6411

The uncertainties associated with the LB6411 survey meter are underestimated as they correspond to the value indicated by the survey meter based only on statistics (number of counts). The measurements with the two systems could therefore be considered in agreement for both neutron fields, providing a high level of confidence on the experimental results. These measurements were therefore used as reference data to test the validity of neutron simulations performed by the MCNP Monte Carlo code taking into account the experimentally determined concrete composition and density.

\section{MCNP SIMULATION - REFERENCE MODEL}

\section{IV.A. Geometry}

The MCNP code ${ }^{12}$ has been used for the simulation. The facility was modeled with all its concrete floors and walls, taking into account the doors. This includes the control room, where the measurements took place. The main equipment in the experimental hall (detectors, support structures, etc.) are included in the simulation to take into account the contribution of scattered neutrons. The control room was filled with a homogeneous material of low density $\left(0.045 \mathrm{~g} . \mathrm{cm}^{-3}\right)$. This material contains all the elements present in this room (wood, acquisition electronics, air, etc.) respecting their mass proportion. The volume of interest (measurement point) was a sphere with a radius of 12 inches filled with air. MCNP "Tally 4 " was used as it allows the calculation of the average flux in this volume. The distance between the source and the center of the measurement position is $10.45 \mathrm{~m}$. As previously stated, the direction of the measurement point is $150^{\circ}$ with respect to the ion beam direction. 


\section{IV.B. Composition of the walls and the air}

The walls were modeled homogeneously using the average "AMANDE" concrete, as defined in Table I, with the addition of $100 \mathrm{~kg} \cdot \mathrm{m}^{-3}$ of steel. This composition is shown in Table II in the line named "homogenous". The steel composition is the one recommended by ${ }^{1}$ for "Steel, Stainless 316L" (material n ${ }^{\circ} 301$ ). The estimated density of the "concrete + steel" mixture was the sum of the measured $2.3 \mathrm{~g} . \mathrm{cm}^{-3}$ concrete density and of the assumed $0.1 \mathrm{~g} . \mathrm{cm}^{-3}$ steel density, i.e. $2.4 \pm 0.2 \mathrm{~g} \cdot \mathrm{cm}^{-3}$. The air composition was based on the one proposed in ${ }^{1}$ for "Air (Dry sea level)" (material $n^{\circ} 4$ ) taking into account a relative humidity of $35 \%$ at $20^{\circ} \mathrm{C}$, corresponding to the measurement conditions. The density of the air was assumed to be $0.0013 \mathrm{g.cm}{ }^{-3}$. So, the quantity of water, as calculated from ${ }^{13}$, was of about $5 \mathrm{~g}$ by $\mathrm{kg}$ of air, i.e. to a mass percentage of hydrogen of $0.0556 \%$ in air. All the volumes are modeled as filled with a homogeneous composition, with the exception of those containing concrete in the case of the sensitivity studies with "inhomogeneous concrete".

\section{IV.C. MCNP neutron sources}

The neutron sources used by MCNP come from calculations with the NeuSDesc software ${ }^{14}$ developed by JRC-Geel. For sensitivity studies, the sources were also calculated using the TARGET code ${ }^{15}$. The neutron emission, following a spherical geometry, was therefore fully described in both angular and energy distributions depending on the emission angle. 90 angles ranging from $0^{\circ}$ to $180^{\circ}$ were considered, each corresponding neutron energy distribution being described with energy bins of a few $\mathrm{keV}$ in width.

All calculations were performed with a total of $2^{31}$ source particles. Statistical uncertainties were lower than $1 \%$ (usually about $0.3 \%$ ) on the total spectrum and less than $5 \%$ on each significant energy bin. 


\section{IV.D. MCNP cross sections}

The cross sections used in the MCNP calculations were those from the Discrete Neutron Data Libraries with the following prioritization: use of the "natural" isotopy with the "60c" ENDF evaluation otherwise known as "42c". Four natural isotopes were not considered in the calculations: ${ }^{2} \mathrm{H},{ }^{15} \mathrm{~N},{ }^{17} \mathrm{O}$ and ${ }^{18} \mathrm{O}$. For the last isotope, no cross sections were available in the used version of MCNP. For the three other elements, due to their low content (respectively $0.015 \%, 0.366 \%$ and $0.038 \%$ of isotopic proportion), it is assumed that their contributions are negligible. These libraries and considerations are not the most recent available and several cross sections of elements impacting the results have new evaluations $\left({ }^{1} \mathrm{H},{ }^{16} \mathrm{O}\right.$ or calcium, for example) and cross-sections values are now available ${ }^{16}$ for the isotopes ${ }^{2} \mathrm{H},{ }^{15} \mathrm{~N},{ }^{17} \mathrm{O}$ and ${ }^{18} \mathrm{O}$. No sensitivity studies were performed with these more recent libraries, as this was not the purpose of this study, but should be done in a further work.

\section{MCNP SIMULATION - SENSITIVITY STUDIES}

\section{V.A. MCNP sensitivity model for concrete type}

A limited number of sensitivity calculations were first conducted on a selection set of the 26 different concrete types proposed by ${ }^{1}$. Indeed, it was assumed that, without any particular knowledge of the concrete involved in the facility, the calculations presented in this work could have been performed with any of these concretes. For these sensitivity tests, five concretes representative of the proposed diversity were selected:

1. No. 76 - "Concrete, Baryte (Type BA)". This concrete is supposed to represent a Baryte's concrete family $\left(\mathrm{n}^{\circ} 76,77,78,79,87\right.$, and 88 ). In this family, the Baryte rate is high (between $32.10 \%$ and $46.34 \%$ ) with a high density between 3.10 and 3.36 .

2. No. 81 - "Concrete, Hanford Dry". The composition of this concrete is quite close to the reference configuration with, however, a low hydrogen content of less than $0.5 \%$. 
This concrete is the extreme of a family of concretes that can be called "dry" $\left(n^{\circ} 81\right.$, 86 and 92).

3. No. 84 - "Concrete, Iron-Portland". This concrete is supposed to represent a Ferrous Concrete family $\left(\mathrm{n}^{\circ} 80,83,84,85,89,90,91\right.$ and 93$)$. For this family, the iron content is important (between $47.4 \%$ and $88.1 \%$ ) with a high density between 3.53 and 5.9 .

4. No. 94 - "Concrete, Oak Ridge (ORNL)". The composition of this concrete is quite close to the reference configuration and represents a family of concretes $\left(\mathrm{n}^{\circ} 94,95\right.$, 96,98 and 100) for which the hydrogen content is between $0.5 \%$ and $1 \%$.

5. No. 97 - "Concrete, Ordinary (NIST)". The composition of this concrete is quite close to the reference configuration with, however, a higher hydrogen content of more than $1.0 \%$. This concrete is the extreme of a family of concretes that can be called "wet" $\left(\mathrm{n}^{\circ} 82,97,98,99\right.$ and 101).

In the following parts of this document, special attention has been paid to concretes no. 94 , as well as no. 81 and no. 97 that are close to the ones expected at AMANDE; no. 81 and no. 97 being respectively the "driest" and "wettest" ones.

\section{V.B. MCNP model sensitivity study}

A second sensitivity study using the MCNP reference model was carried out. The following parameters were modified one by one: TARGET neutron sources replacing those from NeuSDesc; concrete density of $2.3 \mathrm{~g} . \mathrm{cm}^{-3}$ instead of $2.4 \mathrm{~g} . \mathrm{cm}^{-3}$; Hydrogen content in concrete of $0.8 \%$ and $1.0 \%$ instead of $0.62 \%$; material filling the measurement room replaced by air.

In addition, the impact of the measuring system on the neutron spectrum was estimated. Calculations were done with and without the largest polyethylene sphere of HERMEIS (12" radius). "Tally 4" (average flux in the volume) was not suitable for these 
calculations. Indeed, the modeling of a polyethylene sphere in the volume of the Tally 4 prevents its use. So, "Tally 2" (average flux crossing a surface) was employed. Only incoming neutrons multiplied by two were considered. This method was tested and allows, in this special geometry, to obtain results similar to the basic calculation with "Tally 4". These calculations have been performed with the measurement room filled only with air. Furthermore the impact of the outside of the facility was tested by extending the MCNP model up to about 50 meters around the facility. Finally, the impact of concrete inhomogeneity (granulometry) was studied by filling the $40 \mathrm{~cm}$ thick concrete wall with repeated and defined structures. The elementary volume of these structures is a cube of $1 \mathrm{~cm}^{3}$, with adjusted volumes to reproduce the total mass, filled with two kinds of material as presented, in mass percentage, in Table II: "gravel + sand + steel" (with a density of $3.5 \mathrm{~g} . \mathrm{cm}^{-3}$ and a composition, determined from a chemical analysis on sand and gravel from Cadarache area) and "water + cement + steel" (with a density of $1 \mathrm{~g} \cdot \mathrm{cm}^{-3}$ and a composition adjusted to be consistent with the AMANDE concrete presented in Table I). Two rather different spatial distributions of these cubes were implemented in the simulations to study the effect of concrete inhomogeneity.

Table II: Chemical composition of the two kinds of material used for the modeling of the inhomogeneity of the concrete.

\begin{tabular}{|c|c|c|c|c|c|c|c|c|c|c|c|c|c|c|c|c|c|c|c|c|}
\hline Chemical element & $\mathrm{H}$ & c & $\mathrm{N}$ & 0 & $\mathrm{Mg}$ & Al & $\mathrm{Si}$ & $\mathrm{P}$ & S & K & $\mathrm{Ca}$ & $\mathrm{Ti}$ & $\mathrm{Cr}$ & $\mathrm{Mn}$ & $\mathrm{Fe}$ & $\mathrm{Ni}$ & $\mathrm{Zn}$ & Mo & Total & $\begin{array}{l}\text { Density } \\
\left(\mathrm{g} . \mathrm{cm}^{-3}\right)\end{array}$ \\
\hline Homogenous & $0,62 \%$ & $6,15 \%$ & $44,03 \%$ & $0,19 \%$ & $0,62 \%$ & $1,66 \%$ & $11,14 \%$ & $0,00 \%$ & $0,16 \%$ & $0,37 \%$ & $30,07 \%$ & $0,10 \%$ & $0,70 \%$ & $0,11 \%$ & $3,47 \%$ & $0,49 \%$ & $0,00 \%$ & $0,10 \%$ & $99,98 \%$ & 2,4 \\
\hline$\frac{\text { Mixed "gravel + }}{\text { sand + steel" }}$ & $0,00 \%$ & $7,56 \%$ & $0,00 \%$ & $48,21 \%$ & $0,00 \%$ & $0,00 \%$ & $15,82 \%$ & $0,00 \%$ & $0,00 \%$ & $0,00 \%$ & $25,26 \%$ & $0,00 \%$ & $0,54 \%$ & $0,06 \%$ & $2,09 \%$ & $0,38 \%$ & $0,00 \%$ & $0,08 \%$ & $100 \%$ & 3,5 \\
\hline$\frac{\text { Mixed "water + }}{\text { cement + steel" }}$ & $2,65 \%$ & $0,00 \%$ & $0,81 \%$ & $26,17 \%$ & $2,65 \%$ & $7,05 \%$ & $0,11 \%$ & $0,01 \%$ & $0,70 \%$ & $1,55 \%$ & $43,40 \%$ & $0,41 \%$ & $1,89 \%$ & $0,34 \%$ & $10,65 \%$ & $1,33 \%$ & $0,02 \%$ & $0,28 \%$ & $100 \%$ & 1,0 \\
\hline
\end{tabular}

\section{COMPARISON between simulations and experimental DATA}

\section{VI.A. Reference MCNP calculation}

References MCNP calculations correspond to those performed with the initial parameters.

The neutron fluence rate energy distributions simulated by MCNP for the two experimental 
configurations are shown in Figure 2 using lethargy representation (i.e. the fluence in each bin is divided by its width in $\mathrm{MeV}$ and multiplied by the mean energy of this bin). They are compared to the experimental data obtained with the HERMEIS Bonner Sphere System. 
(a)

Source 1 : D-T $\left(15.1 \mathrm{MeV}\right.$ at $\left.0^{\circ}\right)$

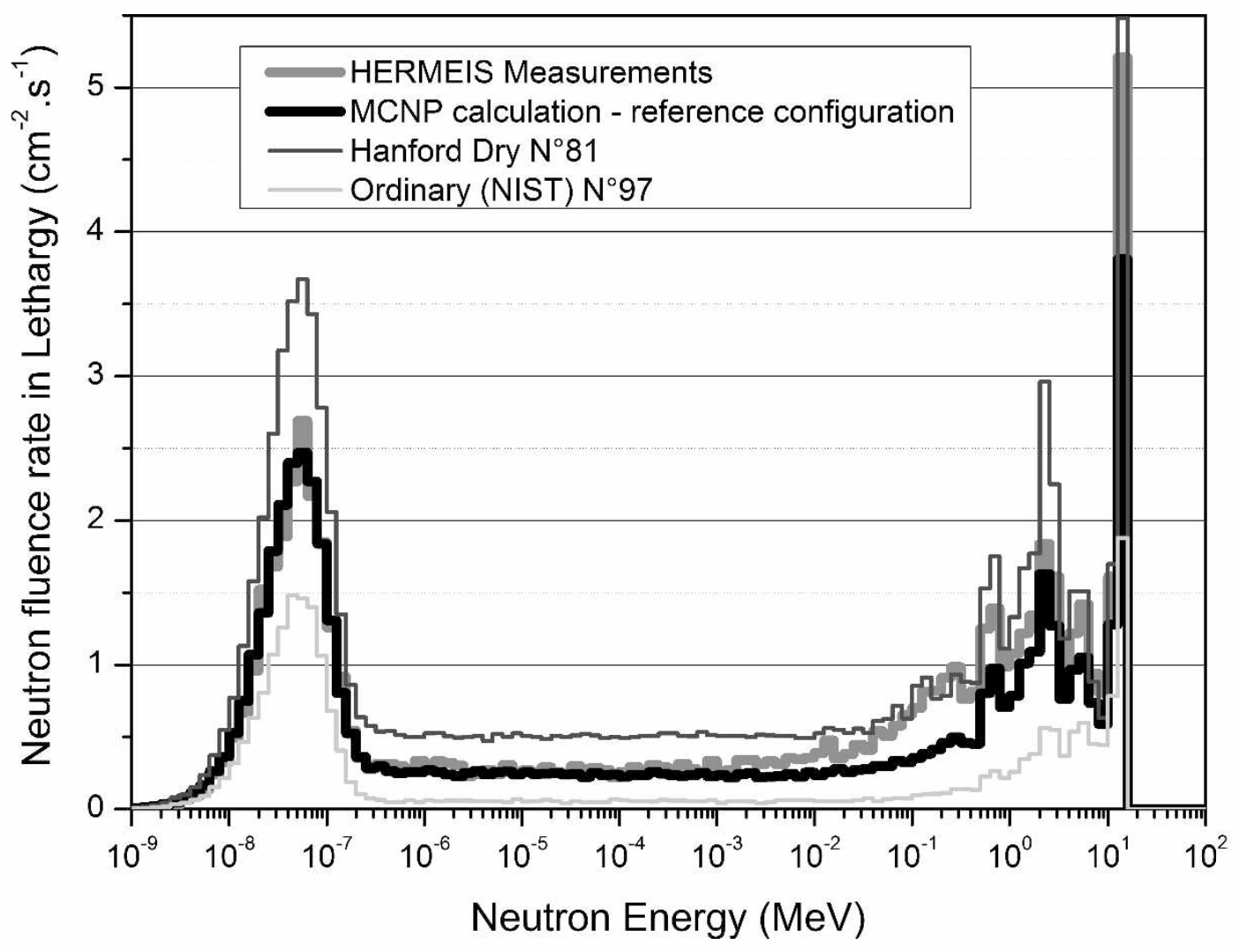




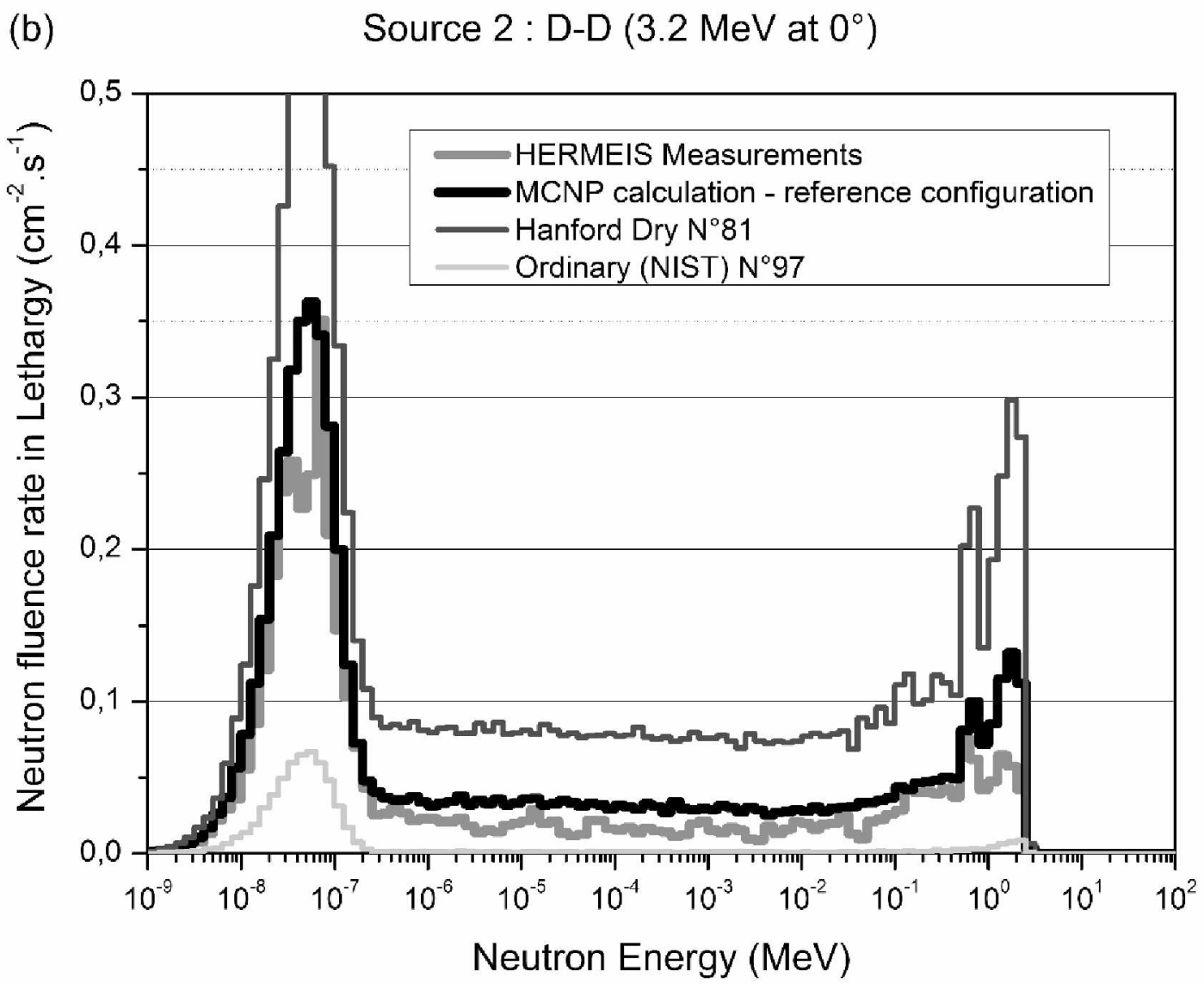

Figure 2: Comparison of the neutron fluence rate energy distributions calculated with MCNP and the measured one with HERMEIS spectrometer for (a) source 1 and (b) source 2. Sensitivity calculations results for the two closest default concrete types ( ${ }^{\circ} 81$ and 97 ) are also shown.

A relatively good agreement is obtained for energy spectra's shape, even if the calculation underestimates the total fluence by $20 \%$ for source 1 (D-T) and overestimates it by $45 \%$ for source 2 (D-D):

1. For source $1\left(13.3 \mathrm{MeV}\right.$ at $\left.150^{\circ}\right)$, the simulated direct (or quasi-direct) neutron component $(13.3 \mathrm{MeV})$ is underestimated by about $25 \%$. Underestimation of the calculation is observed down to $10 \mathrm{keV}$. Below $10 \mathrm{keV}$ the calculated and measured neutron fluence energy distributions are in a rather good agreement. 
2. For source $2\left(2.05 \mathrm{MeV}\right.$ at $\left.150^{\circ}\right)$, the calculated neutron fluence energy distribution is higher than the experimental value over the whole energy range.

Such a discrepancy for source 2 wasn't surprising. Indeed, the macroscopic cross section of concrete, shown in Figure 3 with the contribution of its 3 main isotopes, is about 2 barns at $2.05 \mathrm{MeV}$. The direct attenuation, which is about $3.10^{4}$, can therefore vary by a factor 2 with a modification of only $10 \%$ in the macroscopic cross section (depending on both density and microscopic cross sections).

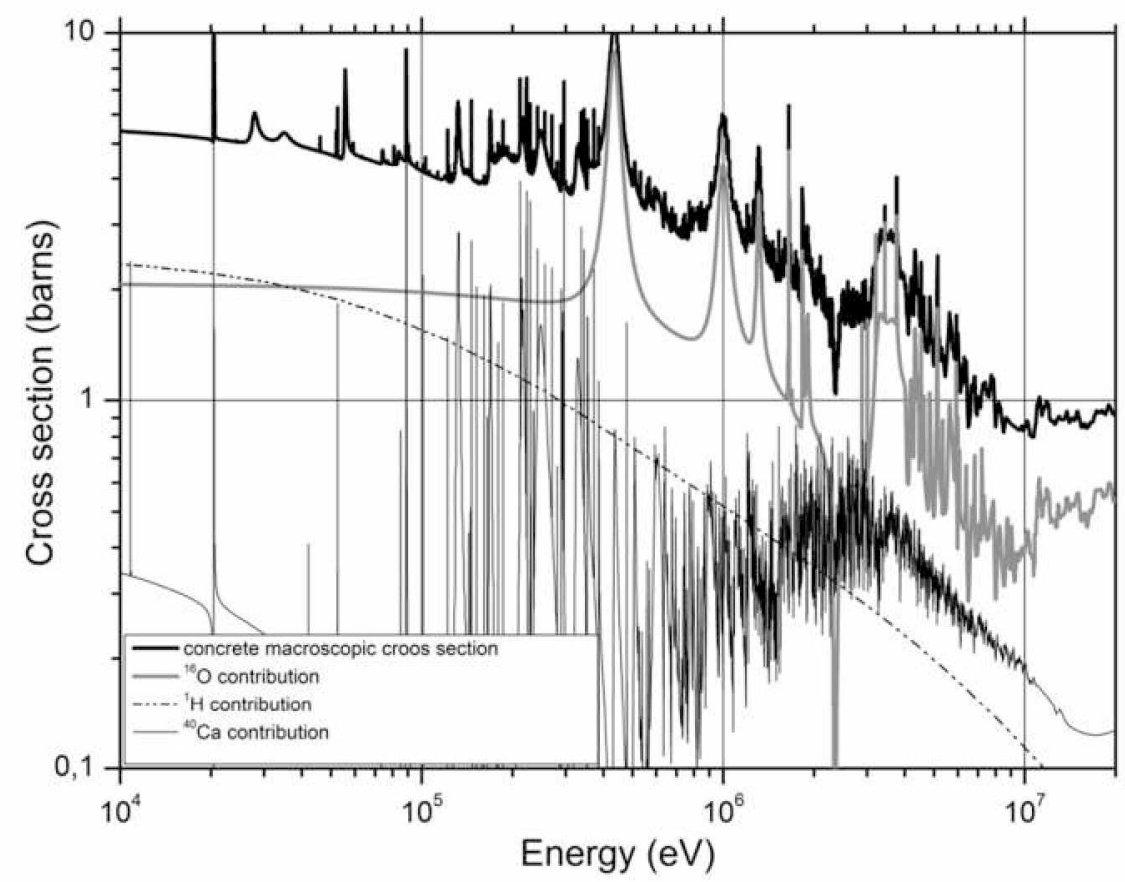

Figure 3: Macroscopic cross section of average AMANDE concrete and contributions from the 3 main isotopes.

In addition, there are significant variations in the cross section around this energy value due to strong Oxygen and Calcium resonances. For source 1, the lower macroscopic cross section value of the concrete (about 0.9 barn) and no important resonances (at least less resolved 
ones) lead to, a priori, a less sensitive configuration to the concrete composition. Nevertheless, a deviation from experimental data is also observed.

The variations in fluences above $100 \mathrm{keV}$ are attributed to minima or maxima in the total macroscopic cross section of the concrete, especially at $2.37 \mathrm{MeV}$, with the wide and deep anti-resonance in the cross section of ${ }^{16} \mathrm{O}$ as mentioned in Goldstein paper ${ }^{17}$. The measurement does not invalidate the presence of these structures.

The good agreement for both sources at thermal energy between measurements and MCNP calculations, for the reference configuration, is another indication of the negligible content of boron in the concrete.

\section{VI.B. Sensitivity study; concrete type and discussion}

Figures 2 show, for both neutron sources, the fluence rate neutron energy distributions for concretes $n^{\circ} 97$ ("wettest") and $n^{\circ} 81$ ("driest"), having the closest composition to AMANDEMIRCOM concrete with the exception of their hydrogen content. Experimental measurements are framed by these two calculations over the whole energy range.

Table III indicate, for both neutron sources, the fluence rates obtained for the five tested concretes, compared to the reference configuration and the HERMEIS measurements. Fluences are given for the whole energy range (indicated as "Total") and by energy group (fast, intermediate and thermal energy ranges). The results are compared to the reference configuration and measurements showing that the reference configuration and concrete $n^{\circ} 94$ are better than any default concrete considered. Indeed, concrete $\mathrm{n}^{\circ} 94$ presents, for both sources, the results closest to the reference configuration and measurements. However, the thermal component is higher, probably because of the larger amount of carbon $(17.5 \%)$ compared to the reference configuration $\left(6.2 \%\right.$ in the AMANDE concrete). Concretes $n^{\circ} 97$ 
("wet" concrete) and concrete $n^{\circ} 84$ ("ferrous concrete") have the highest attenuation values. However, as regard to the mass modeled (factor $\sim 2.5$ ), concrete $n^{\circ} 97$ (Hydrogen content of $2.2 \%$ ) is the one that attenuates the most. Conversely, concrete $n^{\circ} 76$ ("Barite" concrete) and $\mathrm{n}^{\circ} 81$ ("dry" concrete) are the ones that attenuate the least, although compared to its modeled mass, concrete $n^{\circ} 76$ is the least efficient for neutron attenuation. Using the most or the least attenuating concrete leads to deviations of up to an order of magnitude and higher (up to a factor 30) when comparing differences by energy group. This highlights clearly the great importance of accurately knowing the composition of the concrete before performing any simulation.

Table III: Experimental and calculated neutron fluence rates for source 1 (a) and source 2 (b) with the five concretes representative of the proposed diversity.

\begin{tabular}{|l|c|c|c|c|}
\hline (a) & \multicolumn{3}{|c|}{ Neutron fluence rate $\left(\mathrm{cm}^{-2} \cdot \mathrm{s}^{-1}\right)$} \\
\hline Source $1: \mathrm{T}(\mathrm{d}, \mathrm{n})^{4} \mathrm{He}$ & $\begin{array}{c}\text { Total } \\
\mathrm{cm}^{-2} \cdot \mathrm{s}^{-1}\end{array}$ & $\begin{array}{c}\text { Fast } \\
(\mathrm{En}>1 \mathrm{keV})\end{array}$ & $\begin{array}{c}\text { Intermediate } \\
(0,5 \mathrm{eV}<\mathrm{En}<1 \\
\mathrm{keV})\end{array}$ & $\begin{array}{c}\text { Thermal } \\
(\mathrm{En}<0,5 \mathrm{eV})\end{array}$ \\
\hline HERMEIS Measurements & $\mathbf{1 5 , 7 \pm 0 , 9}$ & $\mathbf{6 , 9 1}$ & $\mathbf{3 , 9 3}$ & $\mathbf{4 , 8 7}$ \\
\hline Reference configuration & 12,76 & 4,81 & 3,05 & 4,91 \\
\hline Barite (Type $\mathrm{BA}) \mathrm{n}^{\circ} \mathbf{7 6}(\mathrm{d}=3.35)$ & 18,79 & 5,65 & 5,88 & 7,25 \\
\hline Hanford Dry $\mathrm{n}^{\circ} 81(\mathrm{~d}=2.18)$ & 21,62 & 7,82 & 6,35 & 7,46 \\
\hline Iron-Portland $\mathrm{n}^{\circ} 84(\mathrm{~d}=5.9)$ & 3,09 & 1,44 & 1,34 & 0,30 \\
\hline Oak Ridge $(\mathrm{ORNL}) \mathrm{n}^{\circ} \mathbf{9 4}(\mathrm{d}=2.3)$ & 14,79 & 4,74 & 2,99 & 7,06 \\
\hline Ordinary $(\mathrm{NIST}) \mathrm{n}^{\circ} 97 \mathrm{~d}=2.3$ & 5,50 & 2,02 & 0,68 & 2,80 \\
\hline
\end{tabular}

\begin{tabular}{|l|c|c|c|c|}
\hline (b) & \multicolumn{3}{|c|}{ Neutron fluence rate $\left(\mathrm{cm}^{-2} \cdot \mathrm{s}^{-1}\right)$} \\
\hline Source 2 : $(\mathrm{d}, \mathrm{n})^{3} \mathrm{He}$ & $\begin{array}{c}\text { Total } \\
\mathrm{cm}^{-2} \cdot \mathrm{s}^{-1}\end{array}$ & $\begin{array}{c}\text { Fast } \\
(\mathrm{En}>1 \mathrm{keV})\end{array}$ & $\begin{array}{c}\text { Intermediate } \\
(0,5 \mathrm{eV}<\mathrm{En}<1 \\
\mathrm{keV})\end{array}$ & $\begin{array}{c}\text { Thermal } \\
(\mathrm{En}<0,5 \mathrm{eV})\end{array}$ \\
\hline HERMEIS Measurements & $\mathbf{0 , 9 7 \pm 0 , 0 7}$ & $\mathbf{0 , 1 6}$ & $\mathbf{0 , 2 2}$ & $\mathbf{0 , 5 9}$ \\
\hline Reference configuration & 1,36 & 0,246 & 0,389 & 0,729 \\
\hline Barite (Type $\mathrm{BA}) \mathrm{n}^{\circ}$ 76 (d=3.35) & 1,86 & 0,393 & 0,636 & 0,829 \\
\hline Hanford Dry $\mathrm{n}^{\circ} 81(\mathrm{~d}=2.18)$ & 2,72 & 0,561 & 0,966 & 1,198 \\
\hline Iron-Portland $\mathrm{n}^{\circ} 84(\mathrm{~d}=5.9)$ & 0,19 & 0,066 & 0,100 & 0,023 \\
\hline Oak Ridge (ORNL) $\mathrm{n}^{\circ}$ 94 (d=2.3) & 1,56 & 0,202 & 0,342 & 1,015 \\
\hline Ordinary (NIST) $\mathrm{n}^{\circ}$ 97 $\mathrm{d=2.3}$ & 0,15 & 0,011 & 0,013 & 0,125 \\
\hline
\end{tabular}

\section{IV.C. Sensitivity study on MCNP reference model and discussion}

Table IV present, for both neutron sources, measured and calculated neutron fluence for the reference configuration and sensitivities studies. Results are given over the whole energy 
range including the fast, intermediate and thermal energy ranges. Figure 4 shows neutron fluence rate energy distributions with concrete's inhomogeneity and a hydrogen content of $0.8 \%$. They are presented with MCNP reference calculation and HERMEIS measurements.

Table IV: Experimental and calculated neutron fluence rates for source 1 (a) and source 2 (b) with eight model sensitivity studies.

\begin{tabular}{|l|c|c|c|c|}
\hline (a) & \multicolumn{4}{|c|}{ Neutron fluence rate $\left(\mathrm{cm}^{-2} \cdot \mathrm{s}^{-1}\right)$} \\
\hline Source $1: \mathrm{T}(\mathrm{d}, \mathrm{n}) 4 \mathrm{He}$ & $\begin{array}{c}\text { Fast } \\
(\mathrm{En}>1 \mathrm{keV})\end{array}$ & $\begin{array}{c}\text { Intermediate } \\
(0,5 \mathrm{eV}<\mathrm{En}<1 \mathrm{keV})\end{array}$ & $\begin{array}{c}\text { Thermal } \\
(\mathrm{En}<0,5 \mathrm{eV})\end{array}$ \\
\hline HERMEIS Measurements & $\mathbf{1 5 , 7 \pm 0 , 9}$ & $\mathbf{6 , 9 1}$ & $\mathbf{3 , 9 3}$ & $\mathbf{4 , 8 7}$ \\
\hline Reference configuration & 12,8 & 4,81 & 3,05 & 4,91 \\
\hline Neutrons Source from TARGET & 12,6 & 4,73 & 3,03 & 4,80 \\
\hline Density of 2,3 & 14,1 & 5,47 & 3,38 & 5,27 \\
\hline Hydrogen content of 0,8\% & 10,8 & 4,20 & 2,28 & 4,34 \\
\hline Hydrogen content of 1,0\% & 9,3 & 3,70 & 1,80 & 3,83 \\
\hline Measurement room filled with air & 12,1 & 4,82 & 3,02 & 4,21 \\
\hline Maximum impact of measurement devices & 12,7 & 4,79 & 2,95 & 4,98 \\
\hline inhomogeneity of concrete (modeling 1) & 14,2 & 5,60 & 3,50 & 5,07 \\
\hline inhomogeneity of concrete (modeling 2) & 14,4 & 5,77 & 3,51 & 5,12 \\
\hline
\end{tabular}

\begin{tabular}{|l|c|c|c|c|}
\hline (b) & \multicolumn{4}{|c|}{ Neutron fluence rate $\left(\mathrm{cm}^{-2} \cdot \mathrm{s}^{-1}\right)$} \\
\hline Source 2 : $(\mathrm{d}, \mathrm{n})^{3} \mathrm{He}$ & $\begin{array}{c}\text { Fast } \\
(\mathrm{En}>1 \mathrm{keV})\end{array}$ & $\begin{array}{c}\text { Intermediate } \\
(0,5 \mathrm{eV}<\mathrm{En}<1 \mathrm{keV})\end{array}$ & $\begin{array}{c}\text { Thermal } \\
(\mathrm{En}<0,5 \mathrm{eV})\end{array}$ \\
\hline HERMEIS Measurements & $\mathbf{0 , 9 7 \pm 0 , 0 7}$ & $\mathbf{0 , 1 5 5}$ & $\mathbf{0 , 2 2 3}$ & $\mathbf{0 , 5 9 2}$ \\
\hline Reference configuration & 1,36 & 0,246 & 0,389 & 0,729 \\
\hline Neutrons Source from TARGET & 1,33 & 0,243 & 0,374 & 0,714 \\
\hline Density of 2,3 & 1,54 & 0,292 & 0,446 & 0,805 \\
\hline Hydrogen content of 0,8\% & 1,01 & 0,169 & 0,252 & 0,594 \\
\hline Hydrogen content of 1,0\% & 0,75 & 0,116 & 0,160 & 0,472 \\
\hline Measurement room filled with air & 1,26 & 0,247 & 0,381 & 0,632 \\
\hline Maximum impact of measurement devices & 1,38 & 0,241 & 0,386 & 0,750 \\
\hline inhomogeneity of concrete (modeling 1) & 1,60 & 0,328 & 0,490 & 0,781 \\
\hline inhomogeneity of concrete (modeling 2) & 1,60 & 0,330 & 0,481 & 0,785 \\
\hline
\end{tabular}

It can be seen that the MCNP parameters not directly related to concrete have only a limited impact on the results. The filling material for the measurement room has the highest impact, inducing only a variation of $15 \%$ and $8 \%$ in the neutron fluence rate respectively, in the thermal and whole energy range. On the other hand, the concrete modeling has a major impact on calculated fluence rates. Relative variations up to $60 \%$ are observed. The highest variation in fluence, as anticipated, is the result of hydrogen content. Indeed, even with a small proportion of the mass (usually between $0.5 \%$ and $1 \%$ ), the relative number of hydrogen nuclei is about $10 \%$ to $20 \%$, making a significant contribution to the macroscopic cross section of concrete. Moreover, on average, half of neutron energy is lost in proton collision. In 
the end, the number of collisions increases with the amount of hydrogen and the thermalization is more efficient (see Figure 4). For source 1, the underestimation of above $10 \mathrm{keV}$ in simulation suggests that the neutron slowing process could not be correctly modeled. The inhomogeneity of the concrete, composed mainly of gravel, sand, cement and cavities creates a multitude of different attenuation paths for neutrons. Tests with two different concrete filling structures (called "modeling 1" and "modeling 2") were performed showing a significant impact with both sources (see Figure 4). In the case of source 1, the measurements can be better reproduced, in particular above $100 \mathrm{keV}$, with both of these structures (see arrow on Figure 4 (a)). However these structures noticeably increase the gap between measurement and simulation for source 2 . Nevertheless, it proves that concrete inhomogeneity has a significant impact on neutron fluence rate calculation. 
(a)

Source 1 : D-T $\left(15.1 \mathrm{MeV}\right.$ at $\left.0^{\circ}\right)$

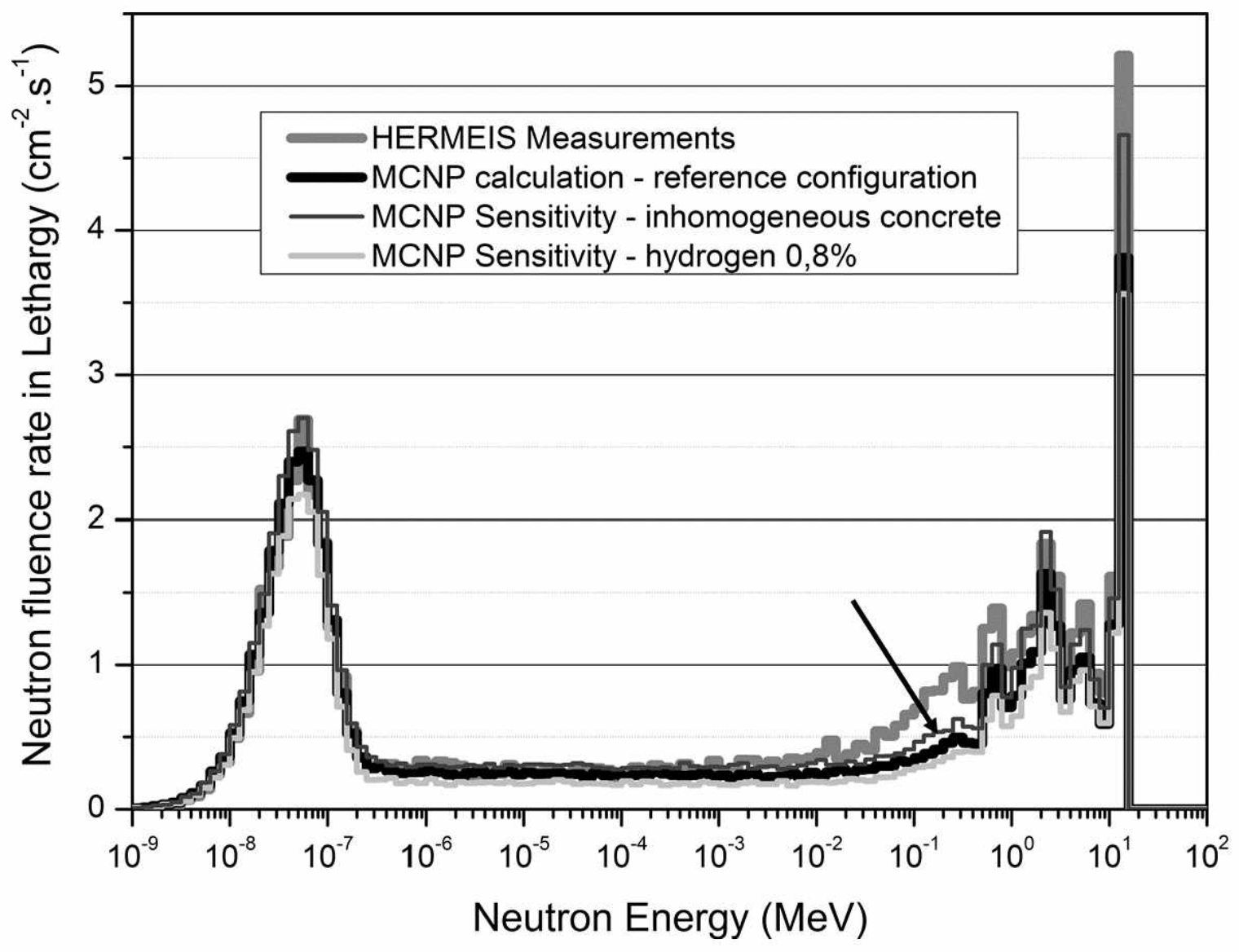




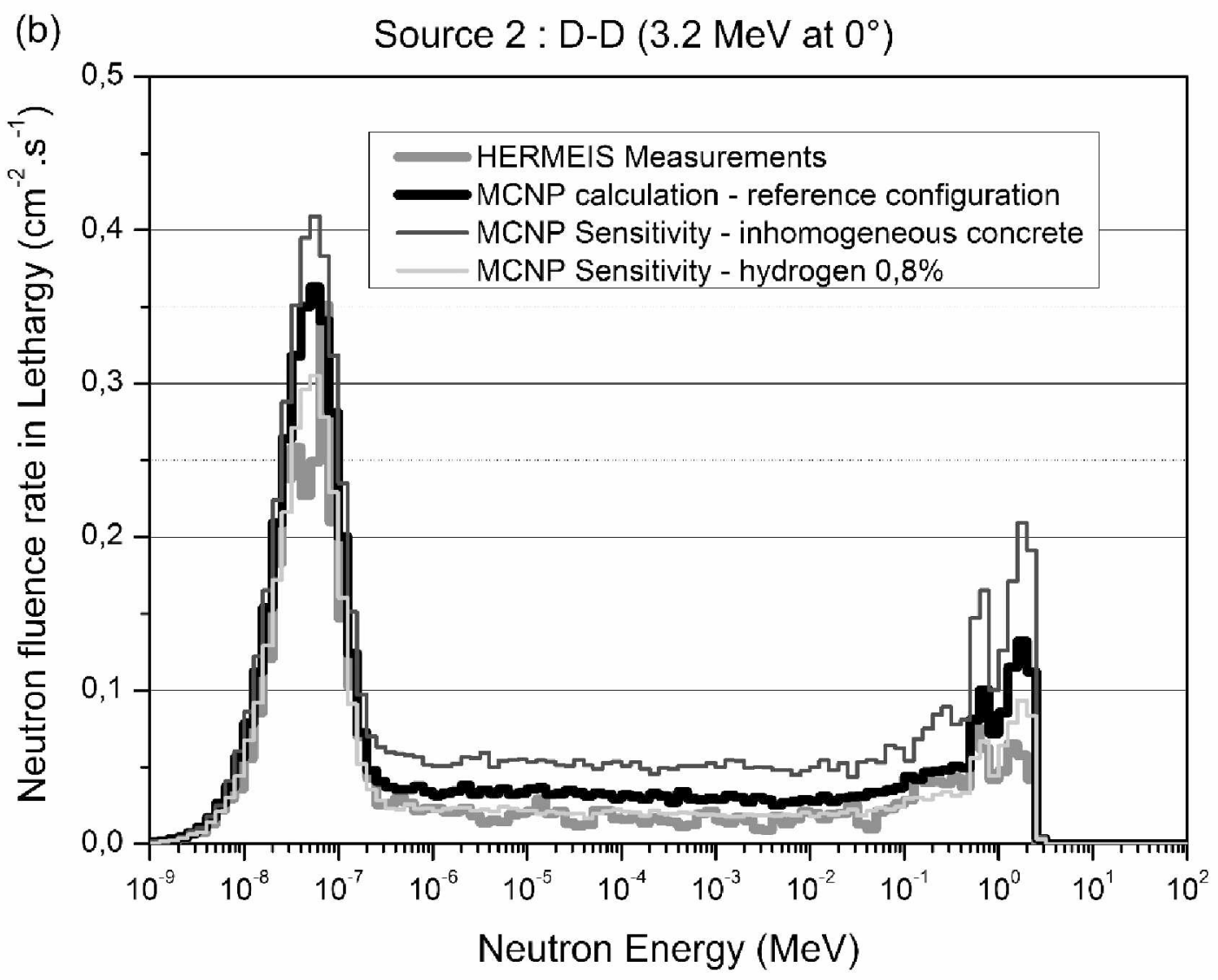

Figure 4: Comparison of the neutron fluence rate energy distributions calculated with MCNP and measured with HERMEIS spectrometer for source 1 (a) and source 2 (b). The results of two sensitivity calculations on the reference configuration are shown. 


\section{CONCLUSION}

The concretes at the AMANDE-MIRCOM facility were analysed and their average chemical compositions were determined. Neutron spectrometry and dosimetry measurements were done with the HERMEIS Bonner Sphere spectrometer and an LB6411 survey meter. Two measurements were made in the facility control room which is protected by a $40 \mathrm{~cm}$ concrete wall. These measurements were done with two monoenergetic neutron fields produced in the experimental hall.

A MCNP simulation of the experiment was carried out with a full description of the neutron source and detailed geometry that included the concrete composition of the experimental facility walls. Comparison of measurement and calculation demonstrate a reasonable level of agreement, within $20 \%$ for one neutron field and $45 \%$ for the second. There were some discrepancies, especially in the fast and the thermal energy ranges.

A first sensitivity study was carried out by choosing five concrete types from the literature according to chemical composition diversity. With the exception of concrete $n^{\circ} 94$, which had a chemical composition and hydrogen content that was close to facility concrete, the simulations with the other four concretes show considerable deviations from the measurements, up to a factor of 10 for the total fluence and a factor of 30 for the fluence in some energy groups.

A second sensitivity study was carried out by MCNP simulation. Six parameters were tested (neutron source simulations, density, hydrogen content, concrete inhomogeneity, the impact of measurement devices and room measurement model details). The results indicate that the main discrepancy between measurement and calculation comes from three specific parameters in concrete modeling: hydrogen content, which is rather difficult to measure; real inhomogeneity, which is challenging to model; and density, which can hardly be determined for an already built concrete wall. 
Despite a huge number of tests, none of the MCNP calculated configurations can reproduce the experimental data obtained with the two neutron fields. Modifying modeling parameters increases the agreement between calculation and measurement from one neutron field dataset and decreases agreement for another.

To better understand these deviations, knowledge and modeling of the density, Hydrogen content and structural concrete inhomogeneity must be improved.

In the end, the modeling of concrete used for calculating the fluence spectra and the associated dose rates is crucial. The user must be able to know or justify his modeling choice. Otherwise his calculation could have a significant deviation. Moreover, even with a special research, users can expect a discrepancy between the experimental and calculated fluency according to neutron spectrometry and concrete thickness.

There is therefore a need of additional studies, both experimental and by simulation, in order to improve the knowledge of neutron transport in concrete.

A sensitivity study of the used nuclear data should be studied, especially using the latest available libraries. In addition, experiments using similar techniques to those carried out in this paper but with other neutron fields, could help to understand the discrepancies.

Other experimental techniques could also be used. For example, the discrepancy for source 1 on the fast component, attributed to the impact of concrete inhomogeneity on neutron transport, could be investigated directly by measuring the neutron transport time in concrete. This measurement does not require an unfolding process, unlike the measurement of the fluence energy distribution. These investigations could be undertaken with a monoenergetic pulsed neutron source and fast detector (scintillator, fission chamber, etc.) placed behind concrete (wall or sample). Moreover, using a neutron spectrometer as fast detector would make possible, with enough statistics, to determine energy distributions as a function of 
transport time. With such experimental data, it would be possible to investigate the slowing down of fast neutrons in the concrete.

\section{Acknowledgments}

The author would like to deeply thanks Dr. Véronique LACOSTE for the provided experimental results and analysis, Dr. Vincent GRESSIER and Isabelle DUHAMEL for extensive discussions and numerous improvements of this manuscript, as well as Paul KLOPPENBERG for his valuable help in upgrading the english quality of the text.

\section{References}

1. RJ. McCONN Jr, CJ. GESH, RT PAGH, RA RUCKER and RG WILLIAMS III, "Compendium of Material Composition Data for Radiation Transport Modeling", PIET-43741-TM-963 PNNL-15870 Rev. 1, PACIFIC NORTHWEST NATIONAL LABORATORY operated by BATTELLE for the UNITED STATES DEPARTMENT OF ENERGY, (March 4, 2001).

2. J. K. SHULTIS, and R. E. FAW, Radiation Shielding, Department of Nuclear Engineering Kansas State University Manhattan, Kansas 66506 - (Copyright 2000).

3. V. S. RAMACHANDRAN and J. J. BEAUDOIN, Handbook of analytical techniques in concrete science and technology. Principles, Techniques, and Applications, NOYES PUBLICATIONS Park Ridge, New Jersey, U.S.A.; WILLIAM ANDREW PUBLISHING, LLC Norwich, New York, U.S.A (2001).

4. Specification for radiation shielding materials, American Nuclear Society, ANSI/ANS-6.4.2-2006.

5. V. GRESSIER et al., "AMANDE: a new facility for monoenergetic neutron fields production between 2 $\mathrm{keV}$ and $20 \mathrm{MeV}$ ". Radiat. Prot. Dosim. Volume 110, Issue 1-4, 1 Pages 49-52, August 2004. https://academic.oup.com/rpd/article/110/1-4/49/1598284

6. V. LACOSTE, "Spectrométrie des neutrons pour la radioprotection en salle de pilotage d'AMANDE" ("Neutrons spectrometry for radiation protection in the AMANDE control room"), IRSN Report, PSESANTE/SDOS/2018-00021 (2018). 
7. "Analyse par technique IGA et PIXE de béton issus de l'installation AMANDE/MIRCOM" ("IGA and PIXE analysis of concrete from the AMANDE-MIRCOM facility"), Analysis report Nº5MP12-14 (April 27, 2015).

8. V. N. PATEL, "Sorptivity testing to assess durability of concrete against freeze thaw cycling", MSThesis, University Montreal Canada, Department of Civil Engineering and Applied Mechanics, (August 2009).

9. A. CHEMINET et al., "Characterization of the IRSN neutron multisphere spectrometer (HERMEIS) at European Standard Calibration fields". IOP Science Journal of Instrumentation, $2^{\text {nd }}$ FNDA, Vol 7 (2012).

10. Berthold Technologies: www.berthold.com/en/neutron-probe-lb-6411.

11. V GRESSIER et al., "Characterization of a measurement reference standard and neutron fluence determination method in IRSN monoenergetic neutron fields", Metrologia 51 431-440 (2014).

12. "MCNPX ${ }^{\mathrm{TM}}$ User's Manual", LA-CP-07-1473, Version 2.6.0, April 2008.

13. Psychometric chart, barometric pressure $760 \mathrm{~mm}$ of Mercury: http://www.uigi.com/UIGI_SI.PDF

14. E. BIRGERSSON and G. LÖVESTAM, "NeuSDesc - Neutron Source Description Software Manual", European Commission, Joint Research Centre, Institute for Reference Materials and Measurements, Scientific and Technical Reports (2007)

15. D. SCHLEGEL, "TARGET user's manual", PTB-6.42-05-2, Braunschweig, (April 2005).

16. D.A. BROWN et al, "ENDF/B-VIII.0. The 8th Major Release of the Nuclear Reaction Data Library with CIELO-project Cross Sections, New Standards and Thermal Scattering Data", Nuclear Data Sheets, Volume 148, February 2018, Pages 1-142.

17. H. GOLDSTEIN, "THE FIELD OF SHIELDING TECHNOLOGY", Neutron Cross Section and Technology. Proceedings of a Conference, Washington, D.C., USA, March 4-7, 1968. NBS Special Publication 299 Volume I, pages 37-52. U.S. DEPARTMENT OF COMMERCE / NATIONAL BUREAU OF STANDARDS. 